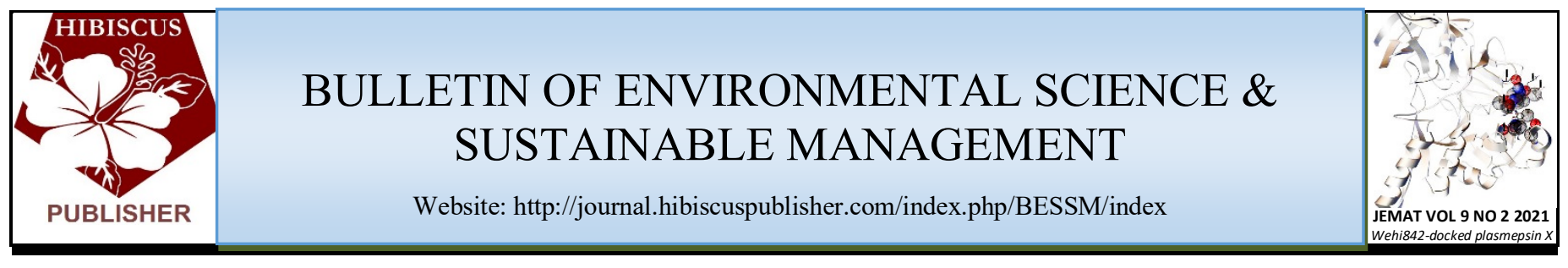

\title{
Kinetics Modeling on the Biosorption of Remazol Black B Dye by Aspergillus flavus
}

\author{
Salihu Yahuza ${ }^{1,3}$, Ibrahim Alhaji $\mathrm{Sabo}^{2,3}$ and Hadiza Aliyu Biu ${ }^{3}$ \\ ${ }^{1}$ Department of Microbiology and Biotechnology, Faculty of Science, Federal University Dutse, P.M.B., 7156, Dutse, \\ Jigawa State, Nigeria. \\ ${ }^{2}$ Department of Microbiology, Faculty of Pure and Applied Sciences, Federal University Wukari, P.M.B. 1020 Wukari, \\ Taraba State Nigeria. \\ ${ }^{3}$ National Commission for Colleges of Education, Abuja, PMB 0394, Garki, Abuja, Nigeria.
}

*Corresponding author:

Salihu Yahuza,

Department of Microbiology and Biotechnology,

Federal University Dutse,

PMB 7156,

Dutse, Jigawa,

Nigeria.

Email: salihu.yahuza@fud.edu.ng

\section{HISTORY}

Received: $15^{\text {th }}$ Aug 2021

Received in revised form: $4^{\text {th }}$ Nov 2021

Accepted: $15^{\text {th }}$ Dec 2021

\section{KEYWORDS}

Kinetics

Nonlinear regression

Biosorption

Remazol Black B

Aspergillus flavus

\begin{abstract}
Azo dyes, such as Remazol Black B, are different from conventional dyes in that they establish covalent bonds with textile fibers like cotton. They are widely utilized in the textile industry because of their favorable properties of bright color, water resistance, simple application procedures, and low energy consumption. Their discharge into receiving streams has major environmental consequences, such as reducing photosynthesis in aquatic life due to lower light penetration. The biosorption isotherm data of Remazol Black B dye biosorption by Aspergillus flavus were investigated using two models - pseudo-1st order and pseudo-2nd order - and fitted using non-linear regression. The pseudo-1st order model was found to be the best by statistical analysis using root-mean-square error (RMSE), adjusted coefficient of determination $\left(\operatorname{adj} R^{2}\right)$, bias factor (BF), accuracy factor (AF), corrected AICc (Akaike Information Criterion), Bayesian Information Criterion (BIC), and Hannan-Quinn information criterion (HQC). At $250 \mathrm{mg} / \mathrm{L}$, kinetic analysis using the pseudo-1st order model yielded an equilibrium sorption capacity $q_{e}$ of $4.61 \mathrm{mg} / \mathrm{g}(95 \%$ confidence interval from 4.54 to 4.68$)$ and a pseudo-1st-order rate constant, $k_{l}$ of 0.15 ( $95 \%$ C.I. from 0.128 to 0.164 ).
\end{abstract}

\section{INTRODUCTION}

Dyes are one of the most important hazardous compounds found in industrial effluents that must be treated because their presence in water bodies reduces light penetration, preventing photosynthesis of aquatic flora as well as being aesthetically objectionable for drinking and other purposes [1]. Azo dyes, such as Remazol Black B, are different from conventional dyes in that they establish covalent bonds with textile fibers like cotton. They are widely utilized in the textile industry because of their favorable properties of bright color, water resistance, simple application procedures, and low energy consumption [2]]. The correct assignment of the kinetics study is critical in understanding the mechanism of biosorption of Remazol Black $\mathrm{B}$ dye. The use of linearization on an obviously nonlinear curve disrupts the error structure of the data. This makes estimating the uncertainty of the kinetics parameters, which are commonly displayed as a 95 percent confidence interval range, even more difficult [3]. Furthermore, the weight assigned to each data point can be changed, which usually results in differences in the fitted parameter values between the linear and nonlinear versions of the kinetics model [4]. In this study, the published data (figure 6) from Biosorption of Remazol Black B dye (azo dye) by growing Aspergillus flavus [[5] is remodelled using different kinetic models, then regressed using nonlinear regression approach, and the best model was determined using various error function analyses. The purpose for this modeling analysis is that in the original paper, there was no modeling exercise for the kinetics.

\section{MATERIALS AND METHODS}

\section{Data Acquisition}

The software Webplotdigitizer 2.5 [6] was used to digitize data from Figure 6 from a published work [5]. The accuracy of digitization using this program has been used and acknowledged by many researchers [7-9]. The data was then nonlinearly regressed using multiple models in the curve-fitting software CurveExpert Professional (Version 2.6.5) (Table 1). 
Table 1. Kinetics Models used in the study

\begin{tabular}{|c|c|c|}
\hline Model & Equation & Reference \\
\hline Pseudo- $1^{\text {st }}$ order & $q_{t}=q_{e}\left(1-e^{-K_{1} t}\right)$ & [9] \\
\hline Pseudo- $2^{\text {nd }}$ order & $q_{t}=\frac{K_{2} q_{e}{ }^{2} t}{\left(1+K_{2} q_{e} t\right)}$ & [10] \\
\hline
\end{tabular}

\section{Statistical analysis}

Corrected AICc (Akaike Information Criterion), Bayesian Information Criterion (BIC), Hannan and Quinn's Criterion (HQ), Root-Mean-Square Error (RMSE), bias factor (BF), accuracy factor (AF), and adjusted coefficient of determination (R2) are some of the most widely used statistical discriminatory methods.

The RMSE was determined using Eq. (1) [11] and it is expected that a lesser number of factors will result in a lower RMSE value. The number of experimental data is $n$, the experimental and projected data are Obi and Pdi, and the number of parameters is p.

$$
R M S E=\sqrt{\frac{\sum_{i=1}^{n}\left(P d_{i}-O b_{i}\right)^{2}}{n-p}}
$$

Because R2, or the coefficient of determination, does not take into account the number of parameters in a model, the adjusted $\mathrm{R}^{2}$ is used to overcome this limitation. The total variance of the $\mathrm{y}$-variable is given by $S_{y}^{2}$ in the equation (Equations 2 and 3), where RMS is the Residual Mean Square.

$$
\begin{aligned}
& \text { Adjusted }\left(R^{2}\right)=1-\frac{R M S}{s_{Y}^{2}} \\
& \text { Adjusted }\left(R^{2}\right)=1-\frac{\left(1-R^{2}\right)(n-1)}{(n-p-1)}
\end{aligned}
$$

The Akaike Information Criterion (AIC) is an information theory-based criterion. It strikes a balance between a model's goodness of fit and its complexity [12]. The corrected Akaike information criterion (AICc) is used to manage data with a large number of parameters or a small number of values (Burnham and Anderson 2002). The AICc is calculated as follows (Eqn. 4), where $p$ represents the number of parameters and $n$ represents the number of data points. A model with a lower AICc value is thought to be more accurate (Burnham and Anderson 2002).

$$
A I C c=2 p+n \ln \left(\frac{R S S}{n}\right)+2(p+1)+\frac{2(p+1)(p+2)}{n-p-2} \text { (Eqn. 4) }
$$

Aside from AICc, the Bayesian Information Criterion (BIC) is another statistical tool based on information theory (Eqn. 5). This error function penalises the number of parameters more precisely than AIC [13]

$B I C=n \cdot \ln \frac{R S S}{n}+k \cdot \ln (n)$

The Hannan-Quinn information criterion (HQC) is another error function approach based on information theory (Eqn. 6). Because of the $\ln \ln n$ term in the equation, the HQC is more consistent than the AIC [14].

$$
H Q C=n \times \ln \frac{R S S}{n}+2 \times k \times \ln (\ln n)(\text { Eqn. } 6)
$$

The Accuracy Factor (AF) and Bias Factor (BF) are two further error function analyses derived from the work of Ross[15].These error functions assess the statistical evaluation of models for goodness-of-fit but do not penalise for a lot of parameters (Eqns. 7 and 8$)$.

Bias factor $=10^{\left(\sum_{i=1}^{n} \log \frac{\left(P d_{i} / O b_{i}\right)}{n}\right)}$

(Eqn. 7)

Accuracy factor $=10^{\left(\sum_{i=1}^{n} \log \frac{\left|\left(P d_{i} / O b_{i}\right)\right|}{n}\right)}$

(Eqn. 8)

\section{RESULTS AND DISCUSSION}

The biosorption isotherm data from a published work [5] on the biosorption of Remazol Black B dye by Aspergillus flavus was examined using two models - pseudo-1st and pseudo-2nd-and fitted with non-linear regression (Figs. 1-2). The pseudo-firstorder model was found to be the best using statistical analysis based on root-mean-square error (RMSE), adjusted coefficient of determination (adjR2), bias factor (BF), accuracy factor (AF), corrected AICc (Akaike Information Criterion), Bayesian Information Criterion (BIC), and Hannan-Quinn information criterion (HQC). At $250 \mathrm{mg} / \mathrm{L}$, kinetic analysis using the pseudo1 st order model yielded an equilibrium sorption capacity $q_{e}$ of $4.61 \mathrm{mg} / \mathrm{g}$ (95\% confidence interval from 4.54 to 4.68 ) and a pseudo-1 st-order rate constant, $k_{l}$ of 0.15 (95\% C.I. from 0.128 to 0.164$)$.

The equilibrium sorption capacity $q_{e}$ in the original published paper was $4.37 \mathrm{mg} / \mathrm{g}$, which is close to the remodeled value. The pseudo- $1^{\text {st }}$ order model, due to its mathematical simplicity has found application together with the pseudo- $2^{\text {nd }}$ order model in modelling numerous dye sorption kinetics [1630]. Some works has suggested mechanism of sorption only basing with the kinetics results, which should not be done, as numerous current works have indicated that more results from isotherm, diffusion and thermodynamics works should be obtained before arriving at the conclusion [31-38].

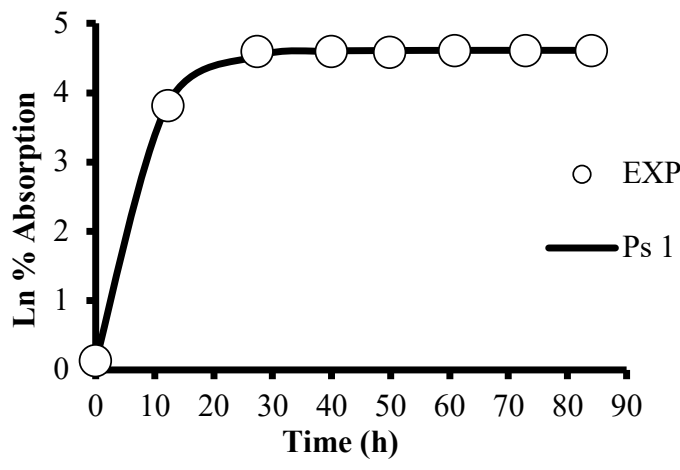

Fig. 1. Kinetic on the Biosorption of Remazol Black dye by Aspergillus flavus modelled using Pseudo-First order model. 


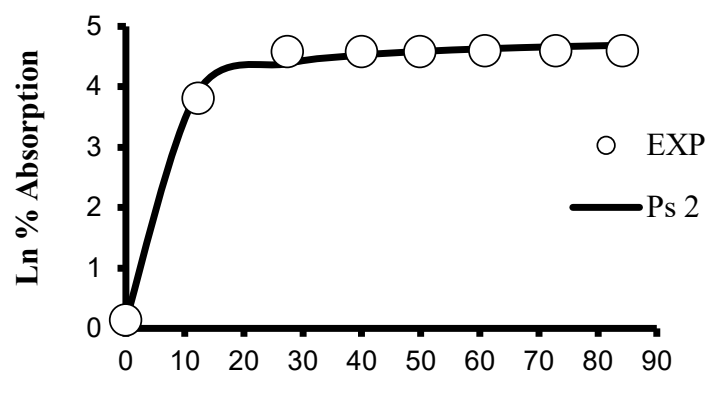

Time (h)

Fig. 2. Kinetic on the Biosorption of Remazol Black dye by Aspergillus flavus modelled using Pseudo-Second order model.

Table 2. Analysis of Error Functions for Regressed models

\begin{tabular}{lrrrrrrrr}
\hline Model & $\mathrm{p}$ & RMSE & $a d R^{2}$ & AICc & BIC & HQC & AF & \multicolumn{2}{c}{ BF } \\
\hline $\begin{array}{l}\text { Pseudo-1st order } \\
\begin{array}{l}\text { Pseudo-2nd } \\
\text { order }\end{array}\end{array}$ & 0.032 & 1.000 & -32.41 & -46.52 & -47.75 & 1.026 & 0.978 \\
& $\mathbf{2}$ & 0.108 & 0.995 & -15.52 & -29.62 & -30.85 & 1.025 & 0.986
\end{tabular}

\section{CONCLUSION}

In conclusion, kinetics modeling on the biosorption of remazol Black B dye by Aspergillus flavus was effectively modelled using two models - pseudo-1st and pseudo-2nd order models, which were fitted using non-linear regression. The pseudo-1st model was found to be the best by statistical analysis using root-meansquare error (RMSE), adjusted coefficient of determination (adjR2), bias factor (BF), accuracy factor (AF), and corrected AICc (Akaike Information Criterion). At $250 \mathrm{mg} / \mathrm{L}$, kinetic analysis using the pseudo-1 st order model yielded an equilibrium sorption capacity $q_{e}$ of $4.61 \mathrm{mg} / \mathrm{g}$ which was similar to the original published paper of $4.37 \mathrm{mg} / \mathrm{g}$.

\section{REFERENCES}

1. Cardoso NF, Pinto RB, Lima EC, Calvete T, Amavisca C V., Royer $\mathrm{B}$, et al. Removal of remazol black B textile dye from aqueous solution by adsorption. Desalination. 2011;269(1-3):92-103.

2. Aksu Z, Tezer S. Equilibrium and kinetic modelling of biosorption of Remazol black B by Rhizopus arrhizus in a batch system: Effect of temperature. Process Biochem. 2000;36(5):431-9.

3. Marbawi H, Arif M, Ros M, Khudri S, Othman AR, Effendi MI, et al. Kinetic analysis of the adsorption of glyphosate onto palm oil fronds activated carbon. Bioremediation Sci Technol. 2019;7(1):29-33.

4. Tran HN, You SJ, Hosseini-Bandegharaei A, Chao HP. Mistakes and inconsistencies regarding adsorption of contaminants from aqueous solutions: A critical review. Water Res. 2017;120:88-116.

5. Ranjusha VR, Pundir R, Kumar K, Dastidar MG, Sreekrishnan TR. Biosorption of Remazol Black B dye (Azo dye) by the growing Aspergillus flavus. J Environ Sci Health - Part ToxicHazardous Subst Environ Eng. 2010;45(10):1256-63.

6. Rohatgi A. WebPlotDigitizer User Manual. HttparohatgiinfoWebPlotDigitizerapp Accessed June 22014. 2013;1-17.

7. Halmi MI, Shukor MS, Johari WL, Shukor MY. Mathematical modeling of the growth kinetics of Bacillus sp. on tannery effluent containing chromate. J Environ Bioremed Toxicol. 2014;31;2(1):610.

8. Yakasai HM, Rahman MF, Gusmanizar N, Shukor MY. Mathematical Modeling of Molybdenum-Blue Production from Bacillus sp. strain Neni. Bioremed Sci Technol Res. 2021;31;9(1):7-12.

9. Ibrahim S, Abdulrasheed M, Ibrahim H, Abubakar A, Yakasai HM. Mathematical Modelling of the Growth of Yeast Candida tropicalis
TL-F1 on Azo Dyes. J Biochem Microbiol Biotechnol. 2021;30;9(1):43-7.

10. Pereira L, Alves M. Dyes-environmental impact and remediation Environ Prot Strateg Sustain Dev. 2012;111-62.

11. Motulsky HJ, Ransnas LA. Fitting curves to data using nonlinear regression: a practical and nonmathematical review. FASEB J. 1987;1(5):365-74.

12. Matsuura M, Sasao T. BDD representation for incompletely specified multiple-output logic functions and its applications to the design of LUT cascades. IEICE Trans Fundam Electron Commun Comput Sci. 2007;E90-A(12):2762-9.

13. Kass RE, Raftery AE. Kass, R.E., Raftery, A.E. (1995).pdf. Journal of the American Statistical Association. 1995. p. 773-95.

14. Korner-Nievergelt F, Roth T, von Felten S, Guélat J, Almasi B, Korner-Nievergelt P. Model Selection and Multimodel Inference. Bayesian Data Analysis in Ecology Using Linear Models with R, BUGS, and STAN. 2015. p. 175-96.

15. Ross T, McMeekin TA. Predictive microbiology. Int J Food Microbiol. 1994;23(3-4):241-64.

16. Dahri MK, Lim LBL, Mei CC. Cempedak durian as a potentia biosorbent for the removal of Brilliant Green dye from aqueous solution: equilibrium, thermodynamics and kinetics studies Environ Monit Assess. 2015 Aug 1;187(8):546.

17. Balarak D, Abasizadeh H, Yang J-K, Shim MJ, Lee S-M. Biosorption of acid orange 7 (AO7) dye by canola waste: Equilibrium, kinetic and thermodynamics studies. Desalination Water Treat. 2020;190:331-9.

18. Deniz F, Kepekci RA. Bioremoval of Malachite green from wate sample by forestry waste mixture as potential biosorbent. Microchem J. 2017 May 1;132:172-8.

19. Aljeboree AM, Alshirifi AN, Alkaim AF. Kinetics and equilibrium study for the adsorption of textile dyes on coconut shell activated carbon. Arab J Chem. 2017 May 1;10:S3381-93.

20. Veleva H. Biosorption of acid dye using quercus coccifera ash Characterization and kinetic modeling. Ser Biomech. 2016;30(3):13-9.

21. Guechi E-K, Hamdaoui O. Biosorption of methylene blue from aqueous solution by potato (Solanum tuberosum) peel: equilibrium modelling, kinetic, and thermodynamic studies. Desalination Water Treat. 2016;57(22):10270-85.

22. Raman MK, Muthuraman G. Application of hyparrheniahirtanovel biosorbent for the effective removal of reactive dyes. Int $\mathrm{J}$ ChemTech Res. 2015;7(7):2860-6.

23. Sánchez-Galván G, Ramírez-Núñez PA. Cationic dye biosorption by Salvinia minima: Equilibrium and kinetics. Water Air Soil Pollut . 2014;225(7).

24. El-Gendy N, Farah J. Performance, kinetics and equilibrium in biosorption of anionic dye Acid Red 14 by the waste biomass of Saccharomyces cerevisiae as a low-cost biosorbent. Turk J Eng Environ Sci. 2013 Jan 1;37:146-61.

25. Weber CT, Foletto EL, Meili L. Removal of tannery dye from aqueous solution using papaya seed as an efficient natural biosorbent. Water Air Soil Pollut. 2013;224(2).

26. Wu Y, Jiang L, Wen Y, Zhou J, Feng S. Biosorption of Basic Violet $5 \mathrm{BN}$ and Basic Green by waste brewery's yeast from single and multicomponent systems. Environ Sci Pollut Res Int. 2012 Feb;19(2):510-21.

27. Kyzas GZ, Lazaridis NK, Mitropoulos AC. Removal of dyes from aqueous solutions with untreated coffee residues as potential lowcost adsorbents: Equilibrium, reuse and thermodynamic approach Chem Eng J. 2012;189-190:148-59.

28. Kumar R, Ahmad R. Biosorption of hazardous crystal violet dye from aqueous solution onto treated ginger waste (TGW). Desalination. 2011;265(1-3):112-8.

29. Zawani Z, Luqman CA, Choong TSY. Equilibrium, kinetics and thermodynamic studies: Adsorption of remazol black 5 on the palm kernel shell activated carbon (PKS-AC). Eur J Sci Res. 2009;37(1):67-76.

30. Gong R, Zhang X, Liu H, Sun Y, Liu B. Uptake of cationic dyes from aqueous solution by biosorption onto granular kohlrabi peel. Bioresour Technol. 2007;98(6):1319-23.

31. Hu Q, Pang S, Wang D. In-depth Insights into Mathematical Characteristics, Selection Criteria and Common Mistakes of Adsorption Kinetic Models: A Critical Review. Sep Purif Rev. 2021 Jul 1;0(0):1-19. 
32. Outram JG, Couperthwaite SJ, Martens W, Millar GJ. Application of non-linear regression analysis and statistical testing to equilibrium isotherms: Building an Excel template and interpretation. Sep Purif Technol. 2021 Mar 1;258:118005.

33. Tran HN, Tomul F, Thi Hoang Ha N, Nguyen DT, Lima EC, Le GT, et al. Innovative spherical biochar for pharmaceutical removal from water: Insight into adsorption mechanism. J Hazard Mater. 2020 Jul 15;394:122255.

34. Tan KL, Hameed BH. Insight into the adsorption kinetics models for the removal of contaminants from aqueous solutions. J Taiwan Inst Chem Eng. 2017 May 1;74:25-48.

35. Tran HN, You S-J, Chao H-P. Insight into adsorption mechanism of cationic dye onto agricultural residues-derived hydrochars: Negligible role of $\pi-\pi$ interaction. Korean $J$ Chem Eng. 2017;34(6):1708-20.

36. Won SW, Kotte P, Wei W, Lim A, Yun Y-S. Biosorbents for recovery of precious metals. Bioresour Technol. 2014;160:203-12.

37. Ghosal PS, Gupta AK. An insight into thermodynamics of adsorptive removal of fluoride by calcined Ca-Al-(NO3) layered double hydroxide. RSC Adv. 2015;5(128):105889-900.

38. Saha P, Chowdhury S. Insight Into Adsorption Thermodynamics. Thermodynamics . 2011 Jan 14 [cited 2020 May 31]; 